\title{
RETHINKING 'KNOWLEDGE EXCHANGE': NEW APPROACHES TO COLLABORATIVE WORK IN THE ARTS AND HUMANITIES
}

\author{
Simon Moreton \\ University of the West of England, REACT Hub, Pervasive Media Studio, Watershed, 1 \\ Canon's Road, Harbourside, BRISTOL, BS1 $5 T X$ \\ +44(0) 1173708879 \\ simon.moreton@uwe.ac.uk
}

\begin{abstract}
This paper explores approaches to collaborative work between arts and humanities disciplines in UK Higher Education and the creative economy. The paper examines the work of four Knowledge Exchange Hubs for the Creative Economy established by the UK Arts and Humanities Research Council (AHRC). These hubs fund collaborative 'knowledge exchange' (KE) projects between creative businesses and academics in the arts and humanities. The paper first outlines the unclear relationship between knowledge exchange activities in HEIs and the creative economy. The second step unpacks the approaches to KE that the hubs are developing. The third step considers what the consequences of such projects might be. The paper concludes that such 'third mission' activities are never neutral or apolitical spaces. Rather, they are sites where assumptions about collaboration and creativity are being remade, and that this is a space for both opportunity and critique.
\end{abstract}

Key words: knowledge exchange; arts and humanities; Higher Education; creative economy; co-production.

\section{Introduction}

In 2011, the UK Arts and Humanities Research Council (AHRC) announced its intentions to invest in a number of regional University consortia to deliver its knowledge exchange programme. A total of $£ 19.2 \mathrm{M}$ (Full Economic Cost) was to be made available to four hubs over four years. Each hub would be charged with improving relationships between Higher Education Institutions (HEIs) and the UK's creative sector; with funding collaborative work between micro-businesses and SMEs and Arts and Humanities researchers; and examining new forms of impact emergent from these activities (AHRC 2011a).

The four successful Knowledge Exchange Hubs for the Creative Economy were awarded funding from late 2011 and were loosely geographical distributed. REACT, based in Bristol focuses on the national creative economy, but HEIs in the South West of England; Creative Works London concentrates on the creative and HEI sector in the UK capital; Creative Exchange, although based in Lancaster, has partnerships with HEIs in London and Newcastle; and Design in Action, based in Dundee has a Scottish remit; These investments were joined by ten 12 month grants for other projects exploring knowledge exchange in the creative economy in 2012, and a cross-research council initiative based in Glasgow called CREATe, established to research and advocate around contemporary copyright and Intellectual Property (IP) challenges in the creative sector.

The decision from the AHRC to experiment with its funding mechanisms, and in particular its focus on developing relationships between arts and humanities 
researchers and the 'creative economy' is of note. The hubs are a departure from the AHRC's earlier KE funding dissemination methods insofar as they represent a devolution of decision making from the AHRC to its funded hubs, and in that it was specifically aimed at using Arts and Humanities research to stimulate innovation in one of the UK's largest growth sectors (AHRC 2011a).

But what happens when the HEI and creative sectors are bought together under the auspices of knowledge exchange? How is knowledge exchange understood? What spaces and practices are forming as the ideas are developed? Are the models used to support KE novel?

This paper considers these questions and attempts to position the emergence of these knowledge exchange initiatives within a broader landscape of social, economic and political change within both the HEI sector and the creative economy. The aim is to identify to what extent the models for collaborative work represented by the hubs diverge from other modes of collaborative HEI work. At the time of writing, the hubs are between 24 and 30 months into a four-year lifetime. As such the discussion presented here is based on interim findings and observations, gathered by the author over the last thirty months in his role as Research Fellow for the REACT Hub. These include findings from the various outputs of the hubs, communications with staff and research teams, and interviews with participants in the REACT KE programme. The research forms part of an on-going process to gather and share learning across all four hubs.

The paper proceeds in two substantive steps. The first unpacks the idea of knowledge exchange as part of a broader series of changes to the UK Higher Education sector. It discusses the underpinnings of the knowledge exchange agenda and situates arts and humanities within that agenda. It points out how an uncertain relationship between HEIs and the creative economy can be found in the AHRC's knowledge exchange activities. The second step explores the example of the hubs as a space where dominant narratives about collaborative work or knowledge exchange are being reconfigured. It provides details of their structures, approaches and outcomes. The paper suggests that in order to understand the both the potential and problematics for new practices of collaborative work between academic and creative sectors, we must avoid a transactional view of collaborative work, such as that offered by dominant knowledge exchange discourses. Instead, a more nuanced view of the sector that recognises contingency, fluidity, formal and informal connections, and network effects, will provide a more critical purchase on the positives and the challenges of collaborative work in this field.

\section{Situating Knowledge Exchange}

The positioning of Universities as global knowledge producers has implicated them in the production of a form of knowledge capitalism (Olssen and Peters 2005). In this context, where knowledge is an economic asset, it is becomes a question of global competitive advantage to produce, and make money from, research knowledge. Activities which support the exploitation of research knowledge have joined the two roles traditionally understood as central to the work of Universities - teaching and researching - to become an important part 'third mission' for HEIs. Accordingly, the idea of the 'entrepreneurial university' in which HEIs foster a research culture that promotes commercialisation via patents, Intellectual Property protection and the establishment of 'spin-out' companies has been noted (Martinelli et al. 2008). These create revenue streams for the institutions, as well as generating networks with private sector companies, industry and government. The model is underpinned by an assertion that universities can contribute to innovation in knowledge-based economies (Etzkowitz and 
Leydesdorff 2000), and it is in this context that discussions around the exchange or transfer of knowledge emerge.

A triple-helix model of relations between academia, industry and government has been identified through which research knowledge can move. Here relations between universities, industry and government sectors, although varied in their strength of connections, build capacity for the flow of codified knowledge, talent in the form of researchers or students trained in a university environment and seeking employment in partner institutions, or otherwise establish local economically competitive clusters.

The terminology used to describe the processes by which 'things' move around the triple-helix model, is frequently one of transfer or exchange. Technology transfer refers to the means by which technology - understood either as a developed 'tool' or as a set of studies, knowledges and practices that are essential to producing a tool - is moved from one institution to another (Bozeman 2000). While this can happen in a business-tobusiness setting, it also occurs in the movement of IP and patents from Unviersity laboratories to R\&D activities in both private and governmental institutions. Knowledge is understood to be transferred, through codified outputs like patents and copyrights which can be licenced to other firms, informal face-to-face interactions in which skills, approaches and ideas can be shared, embodied expertise in the movement of personnel between organisations, and other forms of interactions within innovation networks, such as residencies and consultancy (Döring and Schnellbach 2006). Knowledge transfer or exchange also assumes the importance of the embodied contextual knowledge that surrounds 'tools' or other objects of transfer. It recognises the contingent nature of any knowledge being transferred (Ozga and Jones 2006).

These terms are embedded in a system that understands knowledge as mobile, codifiable and commodifiable (Kenway et al. 2004). This system is often easier to conceptualise in relation to STEM disciplines, that is science, technology, engineering or maths research, because the outputs from those disciplines can often be understood as more tangible; a pharmaceutical molecule; a component for an aeroplane; or an algorithm of use to the computing industry. While this does not mean that mapping or understanding the various forms of relations that surround the production, codification, movement and subsequent development of such outputs is not a complex task, it does suggest that frequently a vision of transfer predicated on tangible STEM outputs takes precedence over the 'soft' outputs of social sciences or humanities (Crossick 2006).

Knowledge exchange and its variant, knowledge transfer, have thus become distinctive terms in the Higher Education lexicon. The terms can be understood to refer to a set of methods or approaches for moving ideas and expertise from academic research to industry, but that do not always have a coherent or commensurate set of definitions within the sector (Geuna and Muscio 2009). The challenge that has emerged for the AHRC's non-STEM disciplines is how to take part in these exchange activities in manner commensurate with the disciplinary practices and outputs of the arts and humanities disciplines. This is difficult especially given the commercial underpinning of many existing knowledge exchange policies where the cultural outputs of the humanities are less ready to be codified or productised (Kenway et al. 2004). Crossick (2006) argues that despite the lack of traditionally 'tangible' outputs from many arts and humanities disciplines, the field has fundamental, if unclear relationships with contemporary economic and social activities. He observes that creating space in which collaboration between different sectors can occur becomes more important than chasing or defining an outcome of knowledge transfer, or a 'widget'. What exactly unfolds in these spaces, is however, unclear. 
Additionally, the motivation for third mission activities extends beyond engagement with a knowledge economy, and into the economic and political situation of the Higher Education sector. Shore and McLauchlan (2012) suggest that the relationship between decreasing state investment, predicated upon a shift to seeing higher education not as a "personal, private investment, rather than a public good" (ibid p. 1) has led to rising demand for value for money for students and an intensified requirement to see 'real world' applications for scholarly knowledge and skills (Shore and McLauchlan 2012). This increased emphasis on social accountability of publicly funded research within the university sector is also visible in the United Kingdom's Research Excellence Framework. Requirements for 'impact' - evidence that the research outputs can have a tangible or measurable effect on stakeholders - are commonplace in funding calls and research programmes (Shore 2008). In these contexts, researchers are compelled to provide evidence as part of national benchmarking systems that research serves, broadly speaking, a public good. Finally, accompanied by stringent cuts to arts and humanities teaching budgets and restructured tuition fee systems in UK universities (Browne 2010), the expectation for HEIs to resource operations both as teaching and research institutions becomes more intense, and finding new ways to raise revenue through other means becomes more imperative.

\section{Repositioning the arts and humanities in knowledge exchange}

Establishing knowledge exchange processes within arts and humanities disciplines has entailed not only repositioning the kinds of outputs the research produces, and how and with whom those researchers can usefully engage, but also negotiating how the value and role of research itself is imagined and valued.

Part of this process for the AHRC has been to rearticulate the value of, and new possibilities for, research in the arts and humanities. A report commissioned by the AHRC, 'Hidden Connections' (Hughes et al. 2011), attempts to quantify and qualify the types of work undertaken by arts and humanities academics in knowledge exchange. The paper recognises that there are a range of motivations for collaborative practice in the arts and humanities that extend beyond only financial gain. These include effecting social change, improving education and cultural understanding. The report also recognises that a range of businesses - not just those working on technological products - benefit from academic knowledge. This report positioned the arts and humanities activities within the field of cultural and creative production, and suggested a variety of outputs, but was not clear on how that relationship might be best managed or capitalised upon, or the production of those outputs managed. Additionally, research strands such as the Cultural Value programme, for example, illustrates a desire to reconsider and articulate cultural value in manner commensurate with both social and economic terms. This research strand explores broadly how the knowledge that emerges from the arts and humanities can be understood as more than only tacit, subjective or cultural that lends itself only to scholarly outputs such as journals, books, teaching or working with cultural institutions in more straightforward capacities (Crossick and Kaszynska 2014).

Another part of this process has been to define the groups outside the academy with whom arts and humanities research can produce meaningful impacts. Knowledge Transfer activities established by the AHRC in the past focused heavily on collaborative doctoral awards, links with traditional cultural organisations and tie-ins to other funding programmes. Other programmes like Connected Communities, in which coproduction of knowledge between academics and local or community stakeholders is encouraged. In this respect, collaboration and co-production have become key parts of the AHRC's contemporary vision for mobilising Arts and Humanities research. The 
Digital R\&D Fund for the Arts, a programme led by Nesta and in partnership with the Arts Council England and AHRC, established the creative sector as a beneficiary of disciplinary knowledge from the arts and humanities. Established in 2012, its remit was to engage or extend audience reach for arts organisations by use of digital technology, or define new business models in the sector (Nesta 2014). Partnerships featured a researcher from an AHRC core discipline to deliver an evaluative research element to each project, or to co-produce solutions to audience challenges. This theme of coproduction was was visible in the AHRC's call for Expressions of Interest in the Knowledge Exchange hubs, in which they defined knowledge exchange as:

\begin{abstract}
the processes by which new knowledge is co-produced through interactions between academic and non-academic individuals and communities. This includes innovative activity brought about by the application of existing knowledge to new contexts. AHRC's interpretation of KE assumes that the new knowledge that is created through such engagements results in significant added value for both the academic and non-academic partners. (AHRC 2011b p. 1)
\end{abstract}

However, this statement, with its focus on co-production with undefined communities, serves to obscure a more specific aim of the hubs, which was to develop, "flexible means for supporting innovative research-based knowledge exchange tailored to the research and skills needs of the Creative Economy." (AHRC 2011a p. 1). This ambition asks the hubs to engage both with the challenges of co-production and community engagement, and the challenge of developing commercial applications of arts and humanities research in the creative sector.

\title{
Exchange in an uncertain field
}

Establishing sustainable partnerships between HEIs and creative businesses has proved problematic, despite a clear desire to explore the value of academic institutions to the creative economy (Comunian et al. 2013). An established connection between arts and humanities and the creative sector is in the nature of the careers adopted by Arts and Humanities graduates (Faggian et al. 2013). A series of research programmes, such as the high-profile Brighton Fuse project have sought to unpack the way in which the activities in the creative sector are related to the work of HEIs. The Brighton Fuse project sought to identify the relationship between academic training, HEIs, creative business and place. Fuse, part-funded by the AHRC, investigated creative clusters, skills, Higher Education training in arts and humanities disciplines, technology and co-location promote growth in the creative sector. Their findings identified a relationship between graduates of arts and humanities disciplines, and the composition of labour in the creative sector (Sapsed and Nightingale 2013).

However, the composition of this sector in terms of its demographic, its geographic distribution, and the size, shape and form of the companies and individuals working within it, make it hard to measure and for HEIs to engage with. Nesta's Manifesto for the Creative Economy (Bakhshi et al. 2013) suggests the sector is characterised by rapid working, small start-ups, the production of cultural goods, the use of new technologies and the development of experiences within the economy. Similarly, the size of HEIs, their work flows and complex systems make it difficult for small creative businesses to find a means to engage with HEIs themselves (Bakhshi et al. 2013).

A desire to find methods to overcome this problem is visible in the interest shown by a number of UK cultural and developmental bodies including Creative England (Channer et al. 2013), the Technology Strategy Board (TSB 2009), Arts Council England and NESTA (as exemplified by their Digital R\&D Fund for the Arts) and the HEI sector itself 
(PACEC 2012). This ambition can be also seen in other documentation that promotes the value of the creative economy to UK development (CIHE 2010, Channer et al. 2013). A part of the challenge has been that the creative sector itself is difficult to define. The creative economy is understood by the AHRC and its partners to comprise a variety of activities of which cultural outputs are their focus. This includes traditional cultural institutions such as theatres, galleries and museums, as well as more commercial activities such as design, digital production, film, television, arts and computer game development associated with the creative industries. They recognise a long-standing relationship between these activities and their core disciplines, from academic roles in the development of literature, music, theatre, the arts, social policy and other forms of connection with sectors outside the academy .

However, the AHRC's categorisations for this sector, and within which it positions its own knowledge exchange initiatives, are broadly commensurate with those of Department of Media, Culture and Sport (DCMS) and the Department for Business and Innovation Skills (BIS). These definitions, and their variable measurement methods have been critiqued both in terms of their classification strategies, and the conceptual or ideological underpinnings that defined them. Various analyses have pointed out the relative difficulties associated with measuring and finding cohesion in the creative industry policies of the last fifteen years (Hewison 2011). The shifting fortunes of these policies can be located within the policy documentation, the definitions and the white papers emerging from the two previous administrations in the UK (DCMS 1998, 2001, 2007,2008 ). Much of the critique surrounds the inconsistent or incoherent attempts to define the creative industries as both an emergent economic sector, and as a space for progressive cultural policy presented in these documents (Hesmondhalgh and Pratt 2005, Pratt 2005, Oakley 2006). Schlesinger describes the creative economy as an illdefined 'doctrine' that guides how the state envisages how business can be done, how competitiveness performed and social value articulated (Schlesinger 2007).

This creative economy script also belies a tension between the idea of creative and cultural practices as being fundamentally linked to social good, at the same time as being an individualising and entrepreneurial force for self-management and economic opportunity (Peck 2005, Oakley 2011). The link to social wellbeing and inclusion (Matarraso 1997, ACE 2005, ACE 2006), derived from earlier Labour cultural policy, for example, was present throughout much creative policy but in actuality, the competitive, consumption led model of creativity has been more dominant (Lee et al. 2011). The idea of creativity and consumption as being linked emerged in many arenas, not least urban development. Work by Florida (2002), Landry (2008) and others on creative cities compelled local authorities, planners and investors to plan urban space in specific ways. Culturally led redevelopments, subsequent gentrification, and the contestation over use of both pre-existing and emergent 'creative' spaces were well-documented (Hall 2000, Balibrea 2001, Evans 2005, Miles 2005, Scott 2006, Pratt 2009). These have also been related to a number of other impacts on the way working subjects are formed, and labour expected to perform. Researchers observed the precarious working conditions in the creative industries (Gill and Pratt 2008, McRobbie 2010), how profoundly unbalanced in terms of gender and ethnicity workplaces often are (Oakley 2011), as well as the emergence of new patterns of career (McRobbie 2002) and lifestyle (Banks 2009, Fougere and Solitander 2010) expectations.

The creative economy script is thus one of contradiction, variable measurements and challenging practices of creative labour. In this sense, the coherence afforded to the creative economy by much of the political commentary suggests an emergent set of businesses and markets with which HEIs can 'engage'. However, as has been pointed out, the creative economy has little in the way of essential compositional characteristics. 
Rather it can be seen as the outcome of a series of measurements, ideas and ideologies about the economic value of cultural work, that map these definitions onto disparate activities (Prince 2014). Dzudzek and Lindner (2013) suggest that with regard to the creative economy, it does not represent a cohesive sector in which things can be done well or badly. Rather it is a messy set of things, people, ideas and relations that has no essential core but, if the political lauding of the sector is anything to go by (DCMS 2008), it is an idea that "has already begun to change and structure the world it assumes to explain" (Dzudzek and Lindner 2013 p. 2). It is within this context of change that the AHRC's hubs are positioned.

\section{Unpacking the AHRC's Knowledge Exchange Hubs for the Creative Economy}

The AHRC's four Knowledge Exchange Hubs for the Creative Economy are initiatives in which the two interrelated scripts - of knowledge exchange and the creative economy come together. In this section the paper first offers an overview of the knowledge exchange hubs and their activities, in an attempt to sketch out the different structures, approaches taken by the hubs, the participants involved and the projects they produce. It then discusses five emergent characteristics of the hubs that require further scrutiny. The varied approaches and methods adopted by the hubs make direct comparison difficult, especially at this interim stage. The delivery models of the hubs span organisational forms, institutional attitudes to key methods and terminologies, and locations. This frequently includes Universities of differing sizes, specialisms and development strategies and cultural institutions; differing approaches to innovation and differing levels of experience working with the creative sector; and a geographically dispersed set of projects. However, there are a few features which unite them; their relative autonomy to operate and disperse funding to creative businesses connects them with similar aspects of the creative economy; their requirement to fund collaborative projects produces similar challenges to brokering and maintaining partnerships; and their remit is to generate evidence for the changing cultures and practices at work in the HEI sector, whether that change is instigated by their own activities, or by external political pressures.

\section{About the hubs}

The hubs are multi-University partnerships. REACT is a consortium project led by the University of the West of England and Bristol digital creativity centre Watershed, in collaboration with the Universities of Bath, Bristol Cardiff and Exeter. There is a subcontract with iShed, part of Watershed, to deliver its Sandbox innovation programme as a primary method for supporting collaborative projects. Creativeworks London is led by Queen Mary University, London. It is a partnership involving 43 London-based research organisations, museums, libraries, archives and industry partners. Creativeworks are also partnered with the EDRF funded project London Creative and Digital Fusion (Creativeworks London 2014). Creative Exchange is a partnership led by Lancaster University, with Newcastle University and the Royal College of Art, London. Their focus is on a concept they refer to as 'digital public space' and the development of products, services and experiences relating to public access to digital space. Design in Action is led by Duncan of Jordanstone College of Art \& Design at the University of Dundee with partners at The University of Abertay, The Glasgow School of Art, Gray's College of Art at the Robert Gordon University, Edinburgh College of Art at the University of Edinburgh and St Andrews University. Design in Action's principle aims are to leverage 'design thinking' into the planning of new business models for Scotland's economy. DiA focus on five sectors; Food, Information Communications Technology, Wellbeing, Sport and Rural Economies. Creativeworks London and REACT feature organisations operating within the cultural or creative 
economy as core delivery partners. This is an important point of difference in that it draws expertise from outside the HEI sector into the delivery of the knowledge exchange programmes.

The hubs' methods for delivering KE differ in how successful projects are supported, but the journey for the applicants is broadly similar, with hubs typically hosting ideas generation events, followed by a brokering and application stage and then a process of direct support to projects awarded funding. Variously described as Ideas Labs (REACT), Ideas Pools (Creativeworks) or creative cafes (Creative Exchange), the idea is that facilitated sessions are held which bring together potential applicants in the hubs' constituent communities of creative businesses and researchers, to generate ideas for bids and partnerships. This stage is followed by a period of brokerage in which members of the hub delivery teams work with potential applicants to shape up ideas, broker relationships where partnerships need additional expertise to realise their projects, and prime partner university organisations on the shape and form of the bids that will be submitted. After successful bidding and award, there follows a production period.

The primary funding model adopted by REACT is delivered as part of a three-month period of R\&D, known as a Sandbox, which gathers together six to eight collaborations working on discrete projects, but around a common theme, such as Heritage or Future Documentary. Collaborations are awarded up to $£ 50,000$, including a $£ 10,000$ grant for the participating company and the rest as costs for academic time and production budget. Creativeworks' models for supporting knowledge exchange include the Creative Voucher Scheme, and other voucher schemes which enable academics to 'buy in' time from creative companies, and for creative companies to 'buy in' academic time (Virani 2014). These knowledge exchange programmes are delivered by The Culture Capital Exchange, a membership organisation who aim to connect HEIs and creative businesses together. These voucher and residency schemes run typically for a period of three to six months., with awards varying between $£ 5,000$ and $£ 15,000$. Companies involved should have been trading for at least 18 months (ibid.). Creative Exchange offer similar amounts for longer term KE projects between researchers and businesses of various sizes, ranging from micro-enterprises to large firms like the $\mathrm{BBC}$. In these projects $\mathrm{PhD}$ students are embedded as researchers, evaluators and scheme designers, and to assist in brokering collaborations. Design in Action deliver a scheme called Chiasma, which entails an ideas generation workshop around a specific theme, where approaches or solutions to problems are discussed between academics and creative. The intellectual property for ideas that are developed is held by DiA. Collaborative teams can then bid for up to $£ 20,000$ to use the IP and develop the idea further, with input from academic researchers where necessary.

The models developed by the hubs are designed to connect academics from AHRC disciplines with companies from a broadly defined creative sector. Academic disciplines engaged have to date included human geography, history, archaeology, English literature, film studies, journalism, sociology, music, design, psychology. A similar demographic is notable between REACT and Creativeworks London, while Creative Exchange and DiA both engage more specifically with applied or design disciplines. A range of disciplines, however, is noted by all the hubs. Creative businesses have included technologists, coders, writers, poets, theatre maker, software developers and app makers (Moreton and Dovey 2013). Business sizes vary, but most hubs report that their work involves partnerships with micro businesses or SMEs. There are a few exceptions, where hubs have engaged with larger companies including software development agencies, or public institutions like the BBC. 
The outputs of the hub's support projects vary, but fall broadly into work that involves digital innovation. Outputs include interactive documentaries, apps, theatre performances, new business models for firms.

\section{Discussion}

So to what is it possible to learn about the field of KE in the arts and humanities from how these different hubs operate? It is possible to identify five emergent aspects from the work of the hubs so far.

Firstly, the different models being developed by the hubs suggest that 'third mission' activities are not monolithic political projects, but rather they are comprised of a travelling set of ideas constituted in different ways (Creativeworks London 2014). Knowledge Exchange Hubs borrow models from different traditions in order to support and broker collaborative work. REACT's Sandbox model, for example, borrows explicitly from work on Open Innovation (Ozga and Jones 2006). This importance given to innovation theory and similar forms of governance practice associated with business and innovation sectors sits alongside the language not only of cultural or artistic development, but also commercialisation. Residency schemes offered by Creativeworks mirror more traditional models of engagement, or are based explicitly on pre-existing innovation voucher schemes (Virani 2014), whilst as the relationships between academics and businesses in the Scottish model represent models for spin outs developed in HEI business schools. Furthermore, these differences are important because they resist an attempt to unify approaches to KE, but instead argue for multiple models to support collaborative work. The requirement to change support processes within HEIs for these KE proects suggests that the way in which the models are being run does not map onto existing methods for supporting knowledge exchange in HEIs. As noted above the hubs have reported a requirement for new processes in contracting and finance which can align the different rates of work, and different approaches to labour management, between the creative and academic sectors.

The nature of these models define how outputs can be imagined. For example, in the instance of REACT, where the development model is borrowed from an R\&D context, there is a focus on widgets and commercial outputs. Similarly, the IP model of DIA, and its conceptual link to Creative Scotland and job creation are directly implicated in the production of new businesses. This economic imperative positions these hubs within the realms of recognisable KE models, where innovation is understood in terms of tangible outputs, products, services or business models. More subtle arguments can be made about the outputs in the notion of the 'slate', borrowed from innovation and venture capital discourse, which suggests a number of projects be supported to develop different outcomes; some high risk, some high growth, and some providing different forms of value. This makes space for other projects within the portfolios of each of the hubs might be considered to align more traditionally with research or arts commissions where outputs are intangible, cultural products, or one-off experiences. As the hubs complete their work in 2016, it will be important to map and contrast the different outputs and consider what role different forms of disciplinary or sectoral approach have played in their constitution.

Secondly, the hubs are experimenting with models that require different forms of labour. The nature of the funding offers short-term residencies, engagement in rapid prototyping processes, or involvement in one-day ideas generation events. Academic engagement in these has been shown to require a different approach to conventional research, operating faster and sharing ideas in novel ways (Moreton and Dovey, 2013). 
Involvement in taking projects through $\mathrm{R} \& \mathrm{D}$ processes to the production of a product also places their activities in a commercial setting.

It could be argued that the hubs are part of a process of neoliberalisation that has resulted in the production of the 'entrepreneurial academic'. This poses challenges for some researchers, for whom the perceived instrumentalisation of academic knowledge damages the freedoms necessary for the production of independent research (Brown and Duguid 1991, Hagel III and Brown 2008). Academic identities are already seen as 'under threat' from changing responsibilities and work patterns (Bullen et al. 2004, Välimaa and Hoffman 2008), neoliberalising processes (Clegg 2008) or the instrumentalisation of research knowledges and bodies (Archer 2008).

On the other hand, many academics involved in Hub activities report a positive experience in being provided with opportunities to work in ways outside of their usual research practices (Moreton and Dovey, 2013). As Wendy Larner (Bullen et al. 2004, Kenway et al. 2004) points out in her response to Shore and McLauchlan (2012), the conditions surrounding third mission activities such as knowledge exchange operate also as a broader set of practices going on within academia more generally. She observes that a desire to co-produce research, share expertise and generate impact in many cases stems from a genuine desire to engage communities outside of academia in the production of knowledge. She notes also that knowledge exchange practices could be linked to questions of accountability in the public sphere and critiques of the 'ivory tower' model of academia. Finally, she recognises that there are new knowledge spaces forming that are concerned with co-production of knowledge that range more broadly than the purely instrumental versions outlined in many critiques of KE. The hubs may well be a space where working in this way provides opportunities for a reconfigured academic practice to emerge. This suggests a need to better understand the relationship between the disciplinary constructions, the spaces, models and subjects of KE in this field.

Thirdly, the hubs imagine the creative economy as a network of mainly microbusinesses which require specialist support. In this respect, the hubs differ from other forms of established knowledge exchange transfer because of the scale, composition and activities of the creative sector and its difference from larger industrial firms more common to STEM knowledge transfer. This is in-line with recent studies that suggest portions of the creative economy are under-reported and under-supported The hubs imagine their companies as small start-ups, but those with different needs to the highvalue, high-growth model of innovative companies recognisable particularly in the software sector (Leicester and Sharpe 2010, Bachmann et al. 2012). Matching administrative processes for these sectors is difficult, and the hubs have noted increasingly the need for new contracting and financial processes within HEIs that are compatible with the working patterns of a micro-business led creative sector. The difficulties presented by establishing KE collaborations between microbusinesses networks and HEIs can lead to a perpetuation of conditions of self-exploitation and precarious labour common to the creative sector (2012). Whether this is through repetitive short-term funding, or slow payment from HEIs of companies involved in KE projects, there is an ethical and economic question about managing sustainable relationships, as well as imagining what the needs and skills of the sector more broadly might be.

Fourthly, the hubs are beginning to argue that the networks created by these dispersed projects require management (Dovey et al. 2014). This includes supporting the formal and informal relationships between microbusinesses, individuals within an institution, and the institutions themselves. This is also a common element of innovation studies, 
where chance encounter and face-to-face contact promote value (Faulconbridge 2006). The hubs are beginning to note the requirement for new forms of expertise to broker and manage the relationships in this network. One embodiment of these expertise is the working subject of the Creative Producer. Geuna and Muscio (Raunig et al. 2011) note that there is an unclear relationship between processes of innovation, the work of university research offices and academic practice. Creative Producers offer different approaches to Research Officers or Knowledge Transfer Officers typically found in HEI Research Offices. Producers operate in multiple ways, acting as boundary spanners between sectors, project managers and advisors to support funded projects, and relationship brokers within the KE network. These roles address many of the needs for 'brokers' in KE projects identified by a number of KE reports (2009) while at the same time providing a new set of skills, specific to the creative and arts sector. These studies have found that the connections between companies, practitioners or individuals in the creative economy are frequently ad hoc and informal (Bakhshi et al. 2013). The creative producer role represent a distinctive set of talents needed in the field of creative innovation in the arts more broadly (CIHE 2010, CIHE 2012). This poses a challenge to how skills and expertise for supporting innovation in HEIs are constituted.

Finally, the hubs are undeniably a political project. The level of promotion the Hubs have received from the AHRC as 'flagship' schemes, the strategic value participating Universities have attached to their involvement, the Hubs' participation in conversations with national development agencies such as BIS, Nesta and TSB and others, all position the work of the Hubs in a space where both methodologies are to be developed, and evidence of success provided. Like work on creative industry policy production, so too do projects become implicated in creating new configurations of policy and practice in a space that spans academic knowledge production, management and exploitation and economic and social development of a strategically important but ill-defined economic sector. In this sense, the learning that is emerging from them, and the models they develop, will be bound into future developments for the AHRC, not only in terms of how it articulates the value of research in its core disciplines, but also about the expertise required to broker how that value is disseminated. As such, they part of broader process of governmentality at work in the HEI sector.

\section{Conclusions}

The AHRC's KE Hubs represent spaces where existing models of knowledge exchange or innovation process are being reconfigured for a different sector. In some instances, this process is resulting in a requirement for new institutional processes, methodologies and working practices. In this sense, they are spaces of policy transfer in action, where ideas are being transported, changed and translated onto different institutional structures (Prince 2012). The diverse forms of structure, management and methodologies visible in the hubs suggest that this process of constitution can have as much to do with everyday individuals, spaces, practices and the mobility of ideas, as it does a coherent political process which underpin their origins (Tyndall 2007). The same can be argued of knowledge exchange policies, where it is the activities of negotiation and production that constitute meaning, spaces and subjects around policy knowledge. The emergent KE landscape described in this paper suggests that the idea of terms like knowledge exchange and creative economy have become constituted, and constitute themselves in different ways. It is possible to see these terms as socially, culturally or economically mobile within this sector. Arguably, they are a space of policy translation or transfer (Prince 2014). Further research is required that builds on the findings reported here in a manner that avoids instantiating KE initiatives as fixed social or political phenomena with more coherence, influence or impact than they necessarily have (Prince 2012). The research should instead focus on moving towards demonstrating how power, spaces 
and subjects operate on the ground. This will involve closer attention to the heterogeneous processes giving rise to the new academic spaces and subjects, the social forms they take and the politics they privilege and subsequently give rise to' (Larner 2011). Analysis of this kind will demonstrate where alternative practices and possibilities, as well as challenges and inequalities, are formed, especially in the contested political space of knowledge exchange in the arts and humanities. 


\section{References}

ACE, 2005. The power of art: visual arts: evidence of impact London: Arts Council England.

ACE, 2006. Visual Arts Policy London: Arts Council England.

AHRC, 2011a. AHRC Knowledge Exchange Hubs for the Creative Economy: Call for Expressions of Interest Swindon: Arts and Humanities Research Council.

AHRC, 2011b. AHRC Knowledge Exchange Hubs for the Creative Economy: FAQs Swindon: AHRC.

Archer, L., 2008. The new neoliberal subjects? Young/er academics' constructions of professional identity. Journal of Education Policy, 23 (3), $265-285$.

Bachmann, G., Dovey, J., Monaco, J. \& Sharpe, B., 2012. Cultural Value Networks Research http://www.dcrc.org.uk/sites/default/files/valuefinalreport_0.pdf:

Digital Cultures Research Centre, University of the West of England.

Bakhshi, H., Hargreaves, I. \& Mateos-Garcia, J., 2013. A Manifesto for the Creative Economy London: Nesta.

Balibrea, M.P., 2001. Urbanism, culture and the postindustrial city: challenging the 'Barcelona model' Journal of Spanish Cultural Studies, 2 (2), 187 - 210.

Banks, M., 2009. Fit and working again? The instrumental leisure of the 'creative class'. Environment and Planning A, 41 ( 3), 668 - 681.

Bozeman, B., 2000. Technology transfer and public policy: a review of research and theory. Research Policy, 29 (4-5), 627-655 Available from: http://www.sciencedirect.com/science/article/pii/S0048733399000931.

Brown, J.S. \& Duguid, P., 1991. ORGANIZATIONAL LEARNING AND COMMUNITIES-OF-PRACTICE: TOWARD A UNIFIED VIEW OF WORKING, LEARNING, AND INNOVATING. Organization Science, 2 (1), 40-57 Available from: http://search.ebscohost.com/login.aspx?direct=true \&db=ehh\&AN=4433 760\&site $=$ ehost-live.

Browne, J., 2010. Securing a sustainable future for higher education: an independent review of higher education funding and student finance. London.

Bullen, E., Robb, S. \& Kenway, J., 2004. 'Creative destruction': knowledge economy policy and the future of the arts and humanities in the academy. Journal of Educational Policy, 19 (1), 3 - 22.

Channer, J., Paul, 0. \& Lee, C., 2013. Connecting and Growing Businesses through Engagement with Higher Education Institutions Swindon: Arts and Humanities Research Council/Creative England.

CIHE, 2010. The Fuse: Igniting High Growth for Creative, Digital and Information Technology Industries London: Council for Industry and Higher Education.

CIHE, 2012. Key Attributes for Successful Knowledge Transfer Partnerships London: Council for Industry and Higher Education.

Clegg, S., 2008. Academic identities under threat? British Educational Research Journal, 34 (3), 329 - 345. 
Comunian, R., Taylor, C. \& Smith, D.N., 2013. The role of universities in the regional creative economies of the UK: hidden protagonists and the challenge of knowledge transfer. European Planning Studies, 22 (12), 1 21.

CreativeworksLondon, 2014. Creativeworks London Prospectus London: Creativeworks London.

Crossick, G., 2006. Knowledge transfer without widgets: the challenge of the creative economy. Royal Society of Arts in Leeds.

Crossick, G. \& Kaszynska, P., 2014. Under construction: Towards a framework for cultural value. Cultural Trends, 1-12 Available from: http://dx.doi.org/10.1080/09548963.2014.897453 [Accessed 2014/03/30].

DCMS, 1998. The Creative Industries Mapping Document London: Department for Media, Culture and Sport.

DCMS, 2001. Creative Industries Mapping Document London: Department for Culture Media and Sport.

DCMS, 2007. Staying ahead: the economic performance of the UK's creative industries London: DCMS.

DCMS, 2008. Creative Britain: New Talents for a New Economy; a strategy document for the Creative Industries. London: DCMS.

Döring, T. \& Schnellbach, J., 2006. What Do We Know about Geographical Knowledge Spillovers and Regional Growth?: A Survey of the Literature. Regional Studies, 40 (3), 375 - 395.

Dovey, J., Moreton, S., Sparke, S. \& Sharpe, B., 2014. Curating Connectivity Bristol: REACT http://react-hub.org.uk/sites/default/files/WORKING PAPER 3 Curating Connectivity.pdf.

Dzudzek, I. \& Lindner, P., 2013. Performing the Creative-Economy Script: Contradicting Urban Rationalities at Work. Regional Studies, 1-16 Available from: http://dx.doi.org/10.1080/00343404.2013.847272 [Accessed 2014/04/04].

Etzkowitz, H. \& Leydesdorff, L., 2000. The dynamics of innovation: from National Systems and "Mode 2" to a Triple Helix of university-industrygovernment relations. Research Policy, 29 (2), 109-123.

Evans, G., 2005. Measure for Measure: Evaluating the Evidence of Culture's Contribution to Regeneration. Urban Studies, 42 (5/6), 959 - 983.

Faggian, A., Comunian, R., Jewell, S. \& Kelly, U., 2013. Bohemian graduates in the UK: Disciplines and location determinants of creative careers. Regional Studies, 47 (2), 183-2000.

Faulconbridge, J.R., 2006. Stretching tacit knowledge beyond a local fix? Global spaces of learning in advertising professional service firms. Journal of Economic Geography, 6, 517540.

Florida, R., 2002. The rise of the creative class: and how it's transforming work, leisure, community and everyday life New York: Basic Books.

Fougere, M. \& Solitander, N., 2010. Governmentality and the creative class: harnessing Bohemia, diversity and freedom for competitiveness. International Journal of Management Concepts and Philosophy, 4 (1), 41 59.

Geuna, A. \& Muscio, A., 2009. The Governance of University Knowledge Transfer: A Critical Review of the Literature. Minerva, 47, 93 - 114. 
Gill, R. \& Pratt, A.C., 2008. In the Social Factory?: Immaterial Labour, Precariousness and Cultural Work. Theory, Culture and Society, 25 (7/8), 1 $-30$.

Hagel III, J. \& Brown, J.S., 2008. Creation Nets: Harnessing The Potential Of Open Innovation. Journal of Service Science, 1 (2), 27 - 40.

Hall, P., 2000. Creative Cities and Economic Development. Urban Studies, 37 (4), $639-649$.

Hesmondhalgh, D. \& Pratt, A.C., 2005. Cultural industries and cultural policy. International Journal of Cultural Policy, 11 (1), 1 - 13.

Hewison, R., 2011. “Creative Britain”: myth or monument? Cultural Trends, 20 (34), 235-242 Available from: http://dx.doi.org/10.1080/09548963.2011.589703 [Accessed 2014/04/02].

Hughes, A., Kitson, M. \& Probert, J., 2011. Hidden Connections: Knowledge exchange between the arts and humanities and the private, public and third sectors Swindon: Centre for Business Research, University of Cambridge and Arts and Humanities Research Council.

Kenway, J., Bullen, E. \& Robb, S., 2004. The Knowledge Economy, the Technopreneur and the Problematic Future of the University. Policy Futures in Education, 2 (2), 330 - 349.

Landry, C., 2008. The Creative City: A Toolkit for Urban Innovators London: Earthscan.

Larner, W., 2011. C-change? Geographies of crisis. Dialogues in Human Geography, $1 \quad$ (3), 319-335 Available from: http://dhg.sagepub.com/content/1/3/319.abstract.

Larner, W., 2012. Beyond Commercialisation. Social Anthropology, 20 (3), 287 289.

Lee, D.J., Oakley, K. \& Naylor, R., 2011. 'The public gets what the public wants'? The uses and abuses of 'public value' in contemporary British cultural policy. International Journal of Cultural Policy, 17 (3), 289 - 300.

Leicester, G. \& Sharpe, B., 2010. Producing the Future: Understanding Watershed's Role in Ecosystems of Cultural Innovation: International Futures Forum.

Martinelli, A., Meyer, M. \& von Tunzelmann, N., 2008. Becoming an entrepreneurial university? A case study of knowledge exchange relationships and faculty attitudes in a medium-sized, research-oriented university. The Journal of Technology Transfer, 33 (3), 259-283 Available from: http://dx.doi.org/10.1007/s10961-007-9031-5.

Matarraso, F., 1997. Use or Ornament? The Social Impact of Participation in the Arts Bournes Green, Stroud: Comedia.

McRobbie, A., 2002. Clubs to companies: notes on the decline of political culture in speeded up creative worlds. Cultural Studies, 16 (4), 516 - 531.

McRobbie, A., 2010. REFLECTIONS ON FEMINISM, IMMATERIAL LABOUR AND THE POST-FORDIST REGIME. New Formations, 60 Available from: http://gateway.proquest.com/openurl/openurl?ctx_ver=Z39.882003\&xri:pqil:res_ver $=0.2 \&$ res_id=xri:lion\&rft_id=xri:lion:rec:abell:R043 88011.

Miles, M., 2005. Interruptions: Testing the Rhetoric of Culturally Led Urban Development. Urban Studies, 42 (5/6), 889 - 911. 
Moreton, S. \& Dovey, J., 2013. CURATING COLLABORATION: The Experience of Collaborative Innovation in REACT (working paper) http://www.reacthub.org.uk/curating-collaboration/ (accessed 15/04/14): REACT.

Nesta, 2014. Digital R\&D Fund for the Arts http://artsdigitalrnd.org.uk/about/ (accessed 02/12/14).

Oakley, K., 2006. Include Us Out - Economic Development and Social Policy in the Creative Industries. Cultural Trends, 15 (4), 255 - 273.

Oakley, K., 2011. In its own image: New Labour and the cultural workforce. Cultural Trends, 20 (3-4), 281-289 Available from: http://dx.doi.org/10.1080/09548963.2011.589709 [Accessed 2014/04/02].

Olssen, M. \& Peters, M.A., 2005. Neoliberalism, higher education and the knowledge economy: from the free market to knowledge capitalism. Journal of Education Policy, 20 (3), 313-345 Available from: http://dx.doi.org/10.1080/02680930500108718 [Accessed 2014/03/20].

Ozga, J. \& Jones, R., 2006. Travelling and embedded policy: the case of knowledge transfer. Journal of Education Policy, 21 (1), 1 - 17.

PACEC, 2012. Strengthening the Contribution of English Higher Education Institutions to the Innovation System: Knowledge Exchange and HEIF Funding: An executive summary for HEFCE Cambridge: Public and Corporate Economic Consultants.

Peck, J., 2005. Struggling with the Creative Class. International Journal of Urban and Regional Research, 29 (4), 740 - 770.

Pratt, A.C., 2005. Cultural Industries and Public Policy: an Oxymoron? International Journal of Cultural Policy, 11 (1), 31 - 44.

Pratt, A.C., 2009. Urban Regeneration: From the Arts 'Feel Good' Factor to the Cultural Economy: A Case Study of Hoxton, London. Urban Studies, 46 (5\&6), 1041 - 1061.

Prince, R., 2012. METAPHORS OF POLICY MOBILITY: FLUID SPACES OF "CREATIVITY" POLICY. Geografiska Annaler: Series B, Human Geography, 94 (4), 317-331 Available from: http://dx.doi.org/10.1111/geob.12001.

Prince, R., 2014. Consultants and the global assemblage of culture and creativity. Transactions of the Institute of British Geographers, 39 (1), 90-101 Available from: http://dx.doi.org/10.1111/tran.12012.

Raunig, G., Ray, G. \& Wuggenig, U. eds. 2011. Critique of Creativity: Precarity, Subjectivity and Resistance in the 'Creative Industries', London: MayFlyBooks.

Sapsed, J. \& Nightingale, P., 2013. The Brighton Fuse Report Brighton: Brighton Fuse.

Schlesinger, P., 2007. Creativity: from discourse to doctrine? Screen, 48 (3).

Scott, A., 2006. Creative Cities: Conceptual Issues and Policy Questions. Journal of Urban Affairs, 28 (1), 1 - 17.

Shore, C., 2008. Audit culture and illiberal governance: universities and the politics of accountability. Anthropological Theory, 8 (3), 278 - 298.

Shore, C. \& McLauchlan, L., 2012. 'Third Mission' activities, commercialisation and academic entrepreneurs Social Anthropology, 20 (3), 267 - 286.

TSB, 2009. Creative Industries Technology Strategy 2009-2012 London: Technology Strategy Board. 
Tyndall, K., 2007. The Producers: alchemists of the impossible London: Arts Council England and The Jerwood Charitable Foundation.

Välimaa, J. \& Hoffman, D., 2008. Knowledge society discourse and higher education. Higher Education, 56 (3), 265-285 Available from: http://dx.doi.org/10.1007/s10734-008-9123-7.

Virani, T.E., 2014. Mechanisms of collaboration between creative small, medium and micro-sized enterprises and higher education institutions: reflections on the Creativeworks London Creative Voucher Scheme. Creativeworks London Working Paper Series, 4, 1 - 25. 